\title{
DESCONSTRUINDO AS COISAS AQUI EMBAIXO: LOBO ANTUNES, LINGUAGEM E GUERRA
}

\author{
Rodrigo Ordine
}

\begin{abstract}
RESUMO
Este artigo discute, via desconstrução derridiana, o romance de António Lobo Antunes, Boa tarde às coisas aqui embaixo (2003), com base em sua violência semântica, estrutural e temática. Tem-se como hipótese que a violência textual do romance, permeada por significantes silenciosos e/ou afásicos, aponta para um debate sobre as potencialidades de uma narrativa cuja temática de ordem autoritária procura ressignificar.
\end{abstract}

PALAVRAS-CHAVE: Desconstrução; Afasia; Guerra.

\section{Introdução}

C $(7$ stamos limitados pela circularidade de nosso discurso.” Essa citação, tomada por Paul Strathern (2002, p. 55), intenciona sintetizar parte do projeto crítico de Jacques Derrida que procuraria, entre tantas outras coisas, demonstrar que nossa fala estará sempre sujeita à linguagem que utilizamos. Para compreendermos melhor, passemos a um pequeno intermezzo. Em 1940 (Derrida tinha apenas 10 anos), a Argélia - sua terra natal - foi arrastada para a II Grande Guerra. Antes disso, o país nunca tinha lutado e sequer visto um uniforme alemão, mas agora havia se tornado um protetorado do império nazista: a guerra espalhava sua perniciosidade sobre a vida da colônia francesa. Em 1954, irrompeu a Guerra da Argélia e Derrida apoiava o esforço pela independência. Após se formar, em 1957, foi convocado para servir em seu país de origem, no exército francês, como professor das crianças dos soldados franceses e argelinos desse exército. Derrida ficou desolado 
com a escalada das atrocidades cometidas, embora tivesse esperanças de uma Argélia independente. Em 1960, ele retorna à França e imerge numa profunda depressão. Em 1962, a Argélia se torna independente e há um êxodo em massa dos europeus. Arruinava-se, então, o desejo de Derrida de se tornar cidadão de uma Argélia independente e, a partir daquele momento, ele voltaria com frequência a experimentar o que chamou de nostalgerie - neologismo, em francês, criado da união de nostalgie e Algérie.

Em 1970, Derrida perde sua mãe. Em 1971, o filósofo francês retorna à Argélia pela primeira vez desde sua independência - sua nostalgerie iria se tornar ainda mais marcante. Sua obra, a partir de então, começa a se rechear de referências enigmáticas aos lugares de seu passado e de indicaçóes oblíquas de seus sentimentos de indivíduo. Muitos críticos, então, questionaram: mas por que se esquivar? Segundo Strathern, expressar tais sentimentos de forma direta iria, aparentemente, diminuí-los. A vitalidade dos sentimentos seria, logo, limitada somente pela tentativa de abrangê-los em palavras - criando o pharmakon, que tanto cura como envenena, trai e estimula a memória. De acordo com o estudioso de Derrida, o pharmakon, ou escritura, é como o curinga, a carta irregular do baralho: pode não significar coisa alguma. "Palavras são diferença, e não identidade. Deveríamos estar olhando para o quanto as palavras podem significar, não tentando ver o que ela significam" (STRATHERN, 2002, p. 55).

Procurando encaminharmo-nos na análise do romance Boa tarde às coisas aqui em baixo, de António Lobo Antunes, utilizar-nos-emos dessa pequena reflexão introdutória para problematizar a escritura da obra, sua forma e linguagem, intencionando a compreensão da seguinte questão: as características da linguagem narrativa da obra - o fragmento - marcam, linguisticamente, uma violência discursiva como representação da violência militar presente na guerra pela independência angolana?

\section{O que é traduzível?}

Embora esta pesquisa não se insira no campo dos estudos linguísticos, gostaríamos de uma breve inserção nesse mundo para dele extrair certos conceitos necessários ao desenvolvimento de nosso proposto.

No processo de aquisição da linguagem, muitos transtornos podem se dar e prejudicar a maturação dessa linguagem, algo que ainda não se tem. 
Contudo, outros problemas também podem ocorrer quando já se possui tal capacidade: são os transtornos de perda da linguagem. De modo geral, temos as afasias (quando a perda é total) e as disfasias (quando parcial), variando ambas em níveis que dependem da localização e da extensão da lesão cerebral.

Lobo Antunes, como epígrafe introdutória, cita de Bartleby y Compañia, de Vilas-Matas, a frase que, construída por personagem que "conservó enteras su lucidez y su memoria, pero cayó en una confusión total del lenguaje" justificaria a escolha do título de sua obra aqui estudada: “- Bonsoir les choses d'ici bas." ou Boa tarde às coisas aqui em baixo. Tal escolha parece profetizar o trabalho narrativo que será construído por Lobo Antunes. A impossibilidade de compreender a frase da personagem de Vilas-Matas e, por contiguidade, do título do romance do escritor português pode nos lembrar a ideia de Derrida de que, retomando Strathern, "Deveríamos estar olhando para o quanto as palavras podem significar, não tentando ver o que ela significam" (apud STRATHERN, 2002, p. 55), na perspectiva da desconstrução proposta pelo filósofo francês. Vejamos agora como o estudo das afasias nos abre espaço para certas consideraçóes.

No campo da neurolinguística, dois tipos de afasias nos interessam: uma que, com riscos de uma análise reducionista, chama-se afasia de Broca, caracterizada por pouca fala, poucas e curtas oraçóes, predomínio de palavras-frase. Nela, a fala sai errada, com agramatismo e disprosódia. Como o falante tem noção do defeito, fala pouco em decorrência de autocensura. E aí parece se enquadrar a personagem Larbaud, da epígrafe.

$\mathrm{Na}$ afasia de Wernicke, o paciente é fluente, possui uma fala logorreica - o indivíduo fala muito, mas omite palavras, usa neologismos e palavras erradas. $\mathrm{O}$ excesso de fala ocorre porque o paciente não entende o que os outros falam nem o que ele próprio fala: não há capacidade de censura. E aí parecem se inserir muitas das vozes narrativas do romance de Lobo Antunes. ${ }^{2}$

Longe de querer estipular um quadro patológico e prognósticos médicos, propomos a tomada dos conceitos afásicos como metáforas para a com-

\footnotetext{
1 "conservou inteiras sua lucidez e sua memória, mas caiu em uma confusão total de linguagem” (Tradução minha).

2 Uma vez que os conceitos de afasia de Brocka e de Wernicke sáo aqui usados apenas de modo metafórico, aconselhamos a conferência do seguinte estudo para mais informaçóes: NOVAES-PINTO, Rosana do Carmo; SANTANA, Ana Paula. Semiologia das afasias: uma discussão crítica. Psicologia: Reflexão e Crítica, n. 22. v. 3, p. 413-421, dez. 2009.
} 
preensão do processo narrativo da obra. A fim de fugir da noção cômica de uma intervenção médica em pacientes ficcionais, procuremos a aplicabilidade dessas metáforas.

\section{A MEMÓRIA E A GUERRA}

Já no prólogo do romance, percebemos que a narrativa antuniana irá se pautar pela noçấo do impreciso, do vago, do incerto, como se vê no fragmento abaixo:

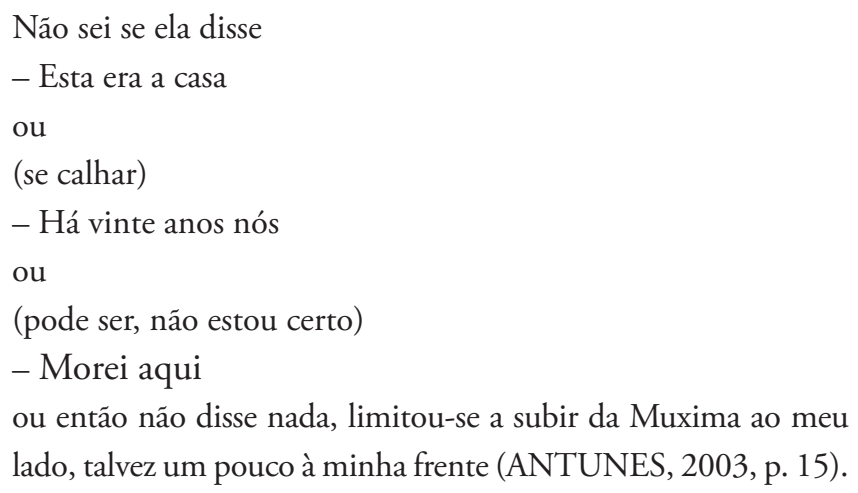

Tal escritura representa muito do que se pode compreender do processo da memória: aquilo que se acha que se sabe ou que foi dito, a escolha seletiva, o silêncio que diz tanto quanto o dito, enfim, caracteres de uma linguagem não linear.

A memória na qual a personagem se apoia abrirá espaço para um dos conceitos mais interessantes de Derrida, aquele que propõe a não fixação de um sentido. A tentativa de atribuir um significado ao texto, como aponta Strathern, "simplesmente eliminaria qualquer outro significado passado que ele possa ter contido, bem como a possibilidade de quaisquer futuras interpretações" (STRATHERN, 2002, p. 56).

Qualquer significado atual imposto ao texto é somente uma ilusão que tenta impor algum significado absoluto. Logo, citando Derrida, Strathern conclui: "A cada vez, a escritura aparece como desaparecimento, rechaço, apagamento, recuo, enroscamento, dispêndio" (STRATHERN, 2002, p. 57). E não seria ingênuo afirmar que toda a escritura de Boa tarde às coisas aqui em 
baixo se pauta nesse processo de "enroscamento" e de "desaparecimento" - neste caso, não só da palavra, mas também de personagens, como se vê em:

a necessidade de chegar a Angola para um trabalhinho simples Miguéis

amigo Miguéis

uma questão de rotina, três ou quatro dias no máximo a fim de limpar os restos que um colega seu

um rapaz sem experiência, bom rapaz mas sem experiência

foi deixado por África e o primeiro resto a limpar é ele mesmo numa fazenda de girassol e algodão a cinquenta ou sessenta quilômetros de Luanda, ele mesmo, uns documentozinhos que poderiam maçar-nos e os diamantes é claro que não recebemos ainda (ANTUNES, 2003, p. 215).

Além do desaparecimento de Seabra, o oficial português cuja missão de recuperar diamantes para o serviço secreto português foi misteriosamente não completada, a constituição política do romance está pincelada em suas entranhas narrativas. $\mathrm{O}$ agente português é eliminado, ao que parece, ao ser transformado em alvo pelo próprio serviço secreto, violência justificada pelo objetivo final: os diamantes e, com eles, a impossibilidade de se ter o conhecimento da existência de uma ação como essa, gerando a queima de arquivo. $\mathrm{O}$ silêncio é imposto pelo "valor" da informação, mais até do que os diamantes. Embora a narrativa seja afásica, i.e., sensorial, excessiva, extensa, sendo uma afasia de Wernicke, muitas personagens são demarcadas pela afasia de Broca: falas breves, curtas, silenciosas em sua completude, mas repetitivas, reiterativas e até traumáticas. Serão esses recursos uma violência ao texto ou do texto? Se sim, será uma maneira de falar da guerra, da violência colonial, descrevendo-as de maneira não linear a fim de enfatizar o dito pelo não dito? São as repetiçôes formas de demarcar o dito pela exaustáo?

A repetição, como vista por Ordine \& Nogueira (2001), pode ser compreendida como uma iteração, isto é, uma repetição em nível enfático, tendo como função reforçar um tema. A repetição pode se dar pela citação de um mesmo termo em várias sentenças ou por uma frase que é reiterada espaçadamente, talvez evocando um conceito. Muitas das vezes, firma-se a derrisão de 
fundamentos e convicçóes pelas repetições, desvanecendo sensaçóes de apoio e perenidade e abrindo espaço para o efêmero, tema que Lobo Antunes evoca ao citar Virgílio, na segunda epígrafe introdutória do romance português: "Há lágrimas na natureza das coisas e a certeza do efêmero toca-nos o coração" (ANTUNES, 2003, p. xi).

A repetição pode possuir qualidades interseccionais com a imitação, recurso que, segundo Margarida Calafate, é uma estratégia de subversão do texto em espaços coloniais que, "pela repetição exaustiva do discurso colonial, adquire um tom irônico e mesmo paródico, [ora] colocando-lhe pequeníssimas diferenças que apontam para a ambivalência discursiva contida no discurso do poder que aparentemente repetem" (CALAFATE, 2004, p. 412). É certo que talvez seja demasiado reducionista (e até falacioso) imprimir um conceito pós-colonial ao romance de Lobo Antunes, mas é também certo que, pela repetição e imitação, a ambivalência do discurso perturba e corrompe a autoridade do serviço secreto português e do sistema da guerra colonial.

Se "o imperialismo francês, como aliás o português, se orientava para a homogeneização dos territórios e populaçóes, com suas teorias de assimilação tendentes a tornar o 'outro' num 'eu', anulando-o, desfigurando-o, desidentificando-o ou tornando-o mesmo uma versão de segunda do 'eu'" (CALAFATE, 2004, p. 18), também os agentes portugueses sofrem desse apagamento - além do sumiço do corpo, da vida, apagamento no universo do bloqueio, da angústia, da incomunicabilidade, fatores também demarcados pela repetição excessiva que se vê nos capítulos do romance.

O silenciamento dos agentes e de outras personagens da obra, seja pela repetição, seja pelo náo dito, pode ser entendido como uma crítica a um segmento da sociedade portuguesa que participou do horror da guerra simplesmente por silenciar: "numa traição, ao enviá-los para África para aí marcarem o tempo de impasse de um regime sem saída" (CALAFATE, 2004, p. 262).

Por fim, a repetição parece traduzir o interminável recomeçar, uma representação exacerbada e profundamente crítica das convençóes e instituiçóes sociais, como círculos concêntricos que se fecham e se abrem no vórtex da condição humana. 


\section{O silêncio diz alguma coisa?}

Depois de estudarmos como o "silêncio", i.e., o não dito, pode, muitas vezes, dizer mais do que o dito, pensaremos como isso se caracteriza num âmbito político-identitário.

Não seria simplificador dizer que o romance de Lobo Antunes é sobre a guerra de independência de Angola e as relaçóes entre Portugal e a colônia africana. Dizer que o romance é somente sobre isso, contudo, seria sim simplificador.

Tomando as noçôes de "silêncio", "repetição" e "apagamento", vistas anteriormente, propomos que pensemos, agora, o que diz esse silêncio, essa repetição e esse apagamento ou, como preferiria Derrida, o que eles poderiam dizer como "indecidíveis" ou "unidades de simulacro", já que aqueles termos "que não se deixam mais compreender na oposição filosófica (binária) e que, entretanto, habitam-na, opóem-lhe resistência, desorganizam-na mas sem nunca constituírem um terceiro termo, sem nunca dar lugar a uma solução na forma da dialética especulativa..." (DERRIDA, 2007, p. 49).

O narrador do capítulo IV, da II parte de Boa Tarde às Coisas Aqui em Baixo, diz: “...há ocasióes em que me pergunto se sobramos nós e as infelizes da ilha ou se as infelizes da ilha são uma ideia nossa..." (ANTUNES, 2003, p. 263). Entrecortando o romance, outros questionamentos sobre quem disse, o que se disse, para quem se disse; ou quem pensa que disse, o que se pensa que se disse e para quem se pensa que se disse são bons exemplos de uma ideia de: a) a identidade do falante; b) a identidade do indivíduo com quem se fala; e c) sobre que identidade se fala.

Tal posicionamento parece indicar algo que Fernando Arenas (2004) entende quando coloca que a literatura portuguesa está povoada de complexas imagens da África e também complexas autoimagens de Portugal, principalmente aquelas que revelam um ressentimento em relação ao declínio (cultural, geopolítico, econômico) do país desde o fim da era das navegaçóes, opinião compartilhada por Eduardo Lourenço, estudado por Arenas. Este mostra que Lourenço compartilha de sua ideia quando"he deconstructs the equation of nation and empire that has dominated the intellectual horizon of Portuguese elites for centuries...”3 (ARENAS, 2004, p. 12), demonstrando que há uma

3 "Ele desconstrói a equação de nação e império que tem dominado o horizonte intelectual das elites portuguesas por séculos.” (Tradução minha) 
lacuna considerável entre as representações historiográficas e as circunstâncias reais do país no mundo. $\mathrm{O}$ fato de Portugal, um país tão pequeno, ter sido tão forte na era das navegaçóes, formatou uma autoimagem portuguesa na qual nação e império estão fortemente ligadas.

É certo que o romance de Lobo Antunes está escrito tendo-se em mente um grupo de cidadãos portugueses não pertencentes à elite - mas sim a uma baixa classe média que, paradoxalmente, representa melhor os mitos de império porque os vivencia no cotidiano. Seabra, um dos narradores do romance, aponta, em sua fala, uma visão de África que, pode-se dizer, está perfeitamente dentro das possibilidades representativas da fala de um cidadão português distanciado da realidade angolana: “... em África chamam cidade a três palhotas desfeitas, chamam cidade a tudo, basta haver uma picada, meia dúzia de cabras com um milhafre em cima, um indígena de pano à cintura a morrer de fome e pronto, cidade..." (ANTUNES, 2003, p. 61).

Por essa fala, percebemos que o que mais importa não é o que se diz, mas o que não se diz por oposição. Se em África "três palhotas desfeitas" é uma cidade, em Portugal não o é. Uma ideia de identidade portuguesa, construída sobre a égide de um conceito de nação imperial, prevalece na fala desse narrador ao mesmo tempo que, ao relatar o caráter precário das cidades angolanas durante a guerra, indica o apagamento de uma noção arquetípico-europeia de cidade, como se na África da guerra não pudessem existir cidades mais ou menos organizadas, mas somente tendas, barracas, cabanas, coordenadas circularmente à moda de bárbaros indígenas.

Nesse sentido, Derrida nos brinda com uma noção de identidade de sentido que pode esclarecer muito do que não se diz ou da busca da compreensão do sentido do que se diz: a formação do sentido ou a autoidentidade do sentido inicia-se a partir de um "abalo de identidade" que se pode entender como um processo de ex-apropriação, noção interpretada por Paulo César Duque-Estrada (2002) da seguinte maneira:

(...) aquilo que vem a formar uma identidade é, ao mesmo tempo, aquilo que já a desloca, que já a abala, já afrouxa os laços de sua própria coesão e, deste modo, não se pode pensar aqui nem em identidade nem em não-identidade, mas sim em um processo contínuo (DUQUE-ESTRADA, 2002, p. 14). 
A crítica que se pode perceber no romance de Lobo Antunes é justamente em relação a essa "identidade" tida como sólida e infinitamente repetida nas falas do cotidiano e na forma de pensar o Eu e o Outro. Sua narrativa é sim uma narração sobre nação, i.e., uma micronarrativa de nação que, como mostra Arenas, indica - assim como outros romances - "a multiplication of subjectivities that speak for their differing individual, group or localized identities and interests" ${ }^{4}$ (ARENAS, 2004, p. 19).

Essa crítica não se dá somente pelo que é dito pelas personagens, mas principalmente pelos silêncios cortantes e repetiçóes angustiantes, como um mote de apagamento de fronteiras, como se vê em narração de Seabra:

telefonando a quem competia ajudar-me o telefone a soluçar sem resposta, perguntando por endereços em cujo lugar num terreno baldio, nenhum prédio, o hotel de que inventaram o sítio, o ministério onde me enviaram de gabinete em gabinete, perdido nos corredores até um contínuo ou uma empregada de limpeza me expulsar para a rua e na rua automóveis americanos sem capot, um pedestal a que faltava a estátua, um candeeiro ao fundo e alcançando o candeeiro o mar, por um instante julguei que Lisboa, o cemitério, a tábua de passar a aferro aberta na marquise, o meu lugar à espera na poltrona sobre o lugar do meu padrasto e do meu pai e afinal as palmeiras da ilha, pássaros que seguiam as traineiras, uma camioneta de soldados (ANTUNES, 2003, p. 70, grifo meu).

Isso só vem a comprovar que, como Duque-Estrada demarca ao estudar os escritos de Derrida, "aqui também já não há mais lugar para se pensar uma unidade original da consciência e da voz - ou seja, do conteúdo ideal de um querer-dizer puro, autônomo, sem nenhum constrangimento empírico..." (DUQUE-ESTRADA, 2002, p. 25/6), e ainda que:

(...) o que quer que funcione como significado, num determinado discurso falado ou escrito, só o faz enquanto desempenha

4 "Uma multiplicação de subjetividades que falam por meio de divergentes identidades e interesses individuais, grupais ou locais." (Tradução minha) 
concomitantemente a função de uma estrutura significante, ou seja, na medida em que já remete a uma outra "coisa", um outro “signo", diferente dele (DUQUE-ESTRADA, 2002, p. 27-8).

\section{Algumas reflexões finais}

A desconstrução sempre foi entendida por Derrida como ferramenta que deve ser usada contra o autoritarismo político e a injustiça, como se vê em sua fala, registrada por Strathern: "A desconstrução deveria buscar uma nova investigação de responsabilidade, questionando os códigos presentes na ética e na política" (STRATHERN, 2002, p. 68). E uma das maneiras de fazer isso seria explodir a linguagem a partir de seu interior, detonando seus significados em uma infinidade de fragmentos de ambiguidade, autocontradição e piadas engraçadas.

Assim, ao tratar da guerra e da monstruosidade que ela representa, parece que um dos caminhos é exaurir o leitor, cansá-lo de repetiçôes e não ditos, gerando a força de diferentes significados, jogos de palavras, ambiguidades associativas que irresistivelmente causam a disseminação de significados, de diferentes interpretaçóes.

Logo, embora a narrativa linear seja violentada pela conduçáo dada por Lobo Antunes, talvez seja uma maneira bem satisfatória de tratar uma narrativa que tem como pano de fundo a guerra colonial que, em sua violência, desterritorializa, despersonaliza e desumaniza. Como mostra ainda Calafate, "da tribuna da memória, testemunhando sobre o que viu, ouviu e viveu, transformando o seu testemunho não apenas na narração de uma agonia pessoal frente à degradação do mundo, mas no espelho de uma agonia colectiva traçada em África" (CALAFATE, 2004, p. 261) e pelo estouro da arma e da bomba, violentamente criam-se afásicos por toda a parte e isso nos impede de atribuir um significado único para "... as coisas aqui em baixo." Torna-se problemático, ainda, assumir que a voz que fala pela nação portuguesa e suas conotaçóes é a mesma que só pode manter o discurso apagando, repetindo e, finalmente, silenciando a si e ao outro como forma de deixar que o sentido possa ser "difícil de distinguir dos pinheiros conforme tenho dificuldade em distinguir a minha neta das ondas do chalé que comprei na Ericeira" (ANTUNES, 2003, p. 560). 


\title{
Referências
}

ANTUNES, António Lobo. Boa tarde às coisas aqui em baixo. Rio de Janeiro: Objetiva, 2003.

ARENAS, Fernando. Utopias of otherness: nationhood and subjectivity in Portugal and Brazil. Minneapolis, MN/USA: University of Minnesota Press, 2004. CALAFATE, Margarida R. Uma história de regressos: império, guerra colonial e pós-colonialismo. Porto: Edições Afrontamento, 2004.

DERRIDA, Jacques. Posiçôes. Trad. Tomaz Tadeu. Minas Gerais: Autêntica, 2007.

DUQUE-ESTRADA, Paulo César (Org.). Derrida e a escritura. In: . $\grave{A s}$ margens. A propósito de Derrida. Rio de Janeiro: Ed. Puc-Rio, 2002. p. 9-28.

ORDINE, Rodrigo; NOGUEIRA, Adelaine L. G. Waiting for Godot: arte e linguagem. Vertentes, n. 18, p. 69-74, São João Del-Rei/MG, julho/dezembro 2001.

STRATHERN, Paul. Derrida em 90 minutos. Rio de Janeiro: Jorge Zahar Ed., 2002.

\section{DECONSTRUCTING THINGS HERE BELOW: LOBO ANTUNES, LANGUAGE AND WAR}

\begin{abstract}
This article discusses, via Derrida's deconstruction, António Lobo Antunes' novel, Boa tarde às coisas aqui embaixo (2003), based on its semantic, structural and thematic violence. It is offered as a hypothesis that the textual violence of the novel, permeated by silent and/or aphasic significants, points to a debate on the potential of a narrative that seeks to reframe a themed authoritarian nature.
\end{abstract}

KEYWORDS: Deconstruction; Aphasia; War.

Recebido em: 17/10/2014 Aprovado em: 10/01/2015 